\title{
Choledochoscopic radiofrequency ablation for congenital choledochal cysts
}

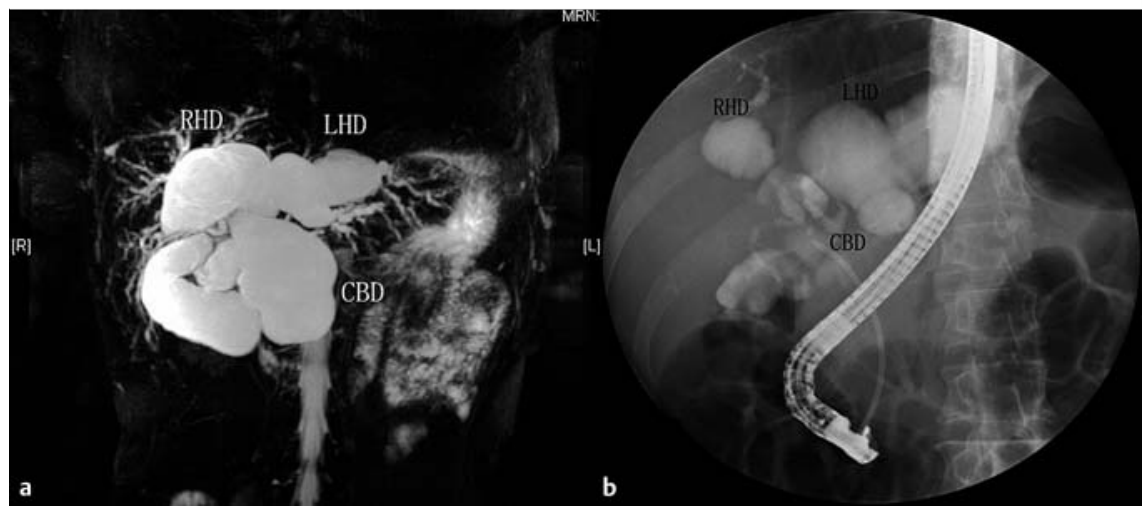

Fig. 1 A type IV-A congenital choledochal cyst as shown by: a dilatations of the intrahepatic bile ducts and the common bile duct on magnetic resonance cholangiopancreatography (MRCP); b saccular dilatations of the intrahepatic and extrahepatic bile ducts on endoscopic retrograde cholangiopancreatography (ERCP). CBD, common bile duct; RHD, right hepatic duct; LHD, left hepatic duct.

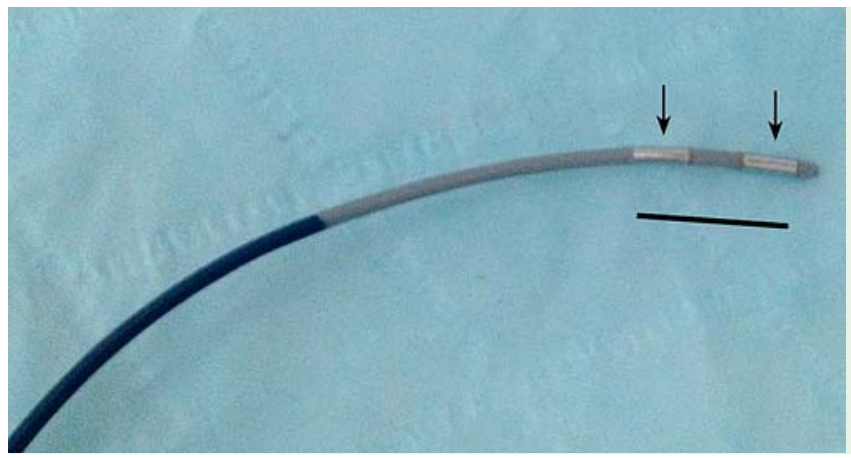

Fig. 2 The Habib EndoHPB catheter, which has a 5 -mm leading tip, then two 8-mm long electrodes (arrows) with an 8-mm separation between them, giving an effective coagulation length of $25 \mathrm{~mm}$ (black line).

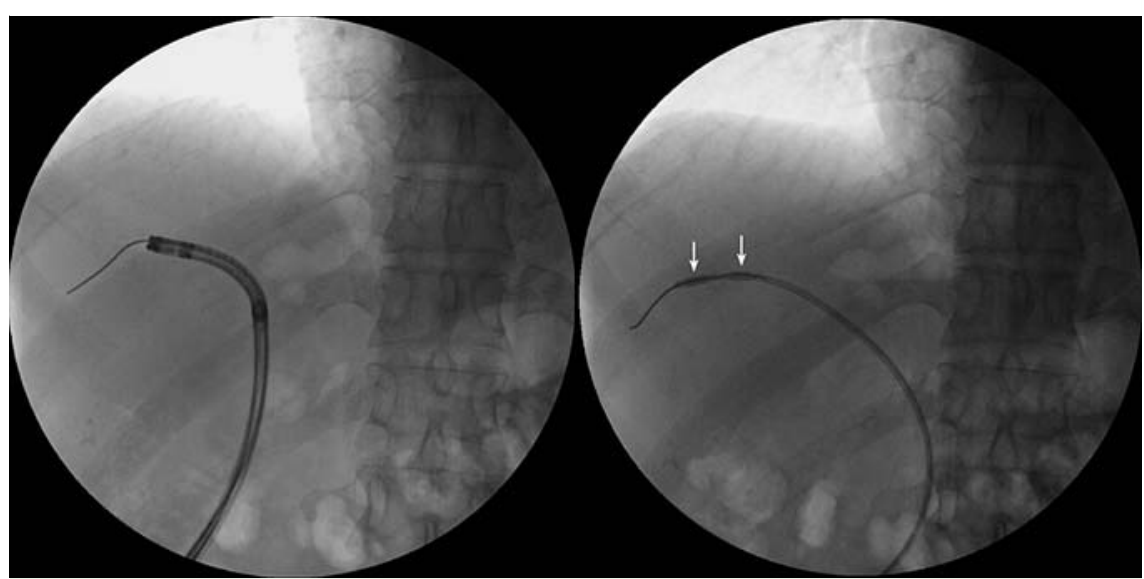

Fig. 3 Radiographic images showing choledochoscope-assisted radiofrequency ablation (RFA) with the wire-guided Habib EndoHPB being applied to the granular lesions of the right hepatic duct. The two electrodes of the catheter are indicated by the arrows.

A 47-year-old man with obstructive jaundice for 20 years consulted our hospital. Magnetic resonance cholangiopancreatography (MRCP) and endoscopic retrograde cholangiopancreatography (ERCP) demonstrated saccular dilatations of the intrahepatic and extrahepatic bile ducts $(\bullet$ Fig. $\mathbf{1})$ and a type IV-A congenital choledochal cyst was diagnosed [1]. He underwent cyst excision of the dilated extrahepatic bile duct with a Roux-en-Y hepaticojejunostomy. Because a frozen section of the biopsy from the hilar bile duct showed high-grade intraepithelial neoplasia, a T-tube was inserted into the common hepatic duct.

Choledochoscopy 3 months later using the Fujinon EO-270F (Fujifilm, Tokyo, Japan), which is $5.1 \mathrm{~mm}$ in diameter at its distal end and has a forceps channel of $2.2 \mathrm{~mm}$ in diameter, revealed granular lesions of the right hepatic duct. Histopathology of these showed tubulovillous adenoma.

Having obtained the informed consent of the patient, we carried out radiofrequency ablation (RFA) of the granular lesions using a choledochoscopic approach. This was done with a wire-guided Habib EndoHPB (Emcision, London, UK) ( $\bullet$ Fig. 2). Ablation was performed using an RFA generator (1500 RF generator; RITA Medical Systems, Fremont, California, USA) delivering electrical energy at $400 \mathrm{kHz}$, set at $10 \mathrm{~W}$ for 90 seconds ( $\bullet$ Fig. 3 and $\bullet$ Fig.4).

Choledochoscopic RFA was repeated ( $\odot$ Fig. 5) for a total of six applications during the following year. Before the third and sixth RFA applications, biopsies were taken from the same place, both of which showed tubulovillous adenoma. The patient has remained under regular followup during the past year. The procedures have been well tolerated and have produced good palliation of his symptoms. Cyst excision is the standard surgical treatment for congenital choledochal cysts because of the risk of subsequent biliary malignancy [2]. However, a complete resection of dilated intrahepatic bile ducts is not a straightforward procedure, so the risk of developing cancer is high [3]. Recently, RFA has become a potential new tool in the management of malignant biliary disease [4]. The use of RFA as a primary treatment for intraductal adenoma has been reported [5]. To our knowledge, this is the first report describing the use of RFA in a patient with congenital choledochal cysts, and the first time choledochoscope-assisted RFA has been performed. Therefore, choledochoscopic RFA is a feasible treatment for congenital choledochal cysts.

Endoscopy_UCTN_Code_TTT_1AR_2AF

Competing interests: None 

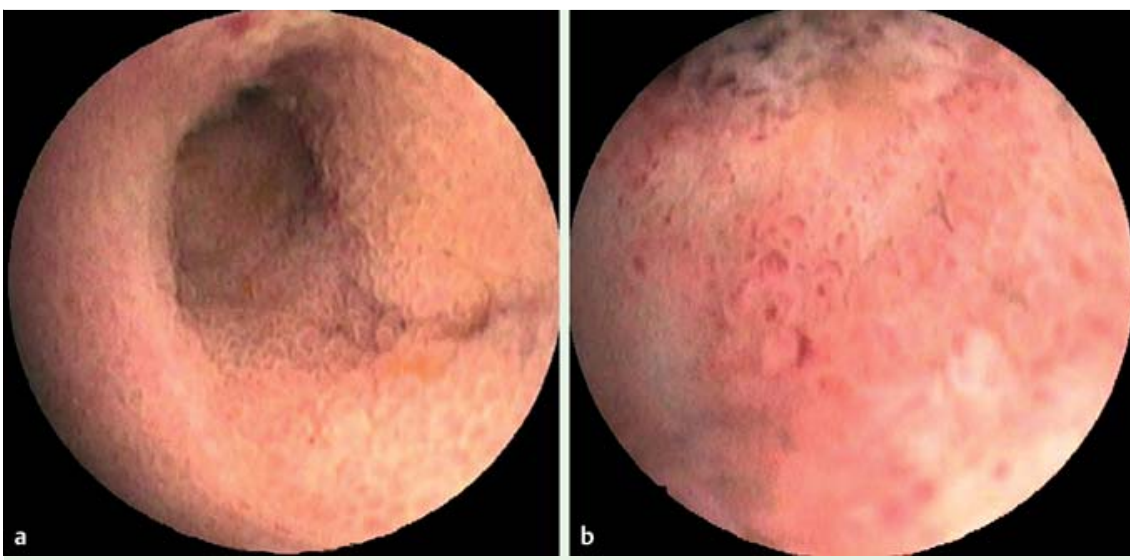

Fig. 4 Views during choledochoscopy showing: a the granular lesions before treatment; $\mathbf{b}$ ablated tumor with reddish coagulated mucosa immediately after the first radiofrequency ablation (RFA);
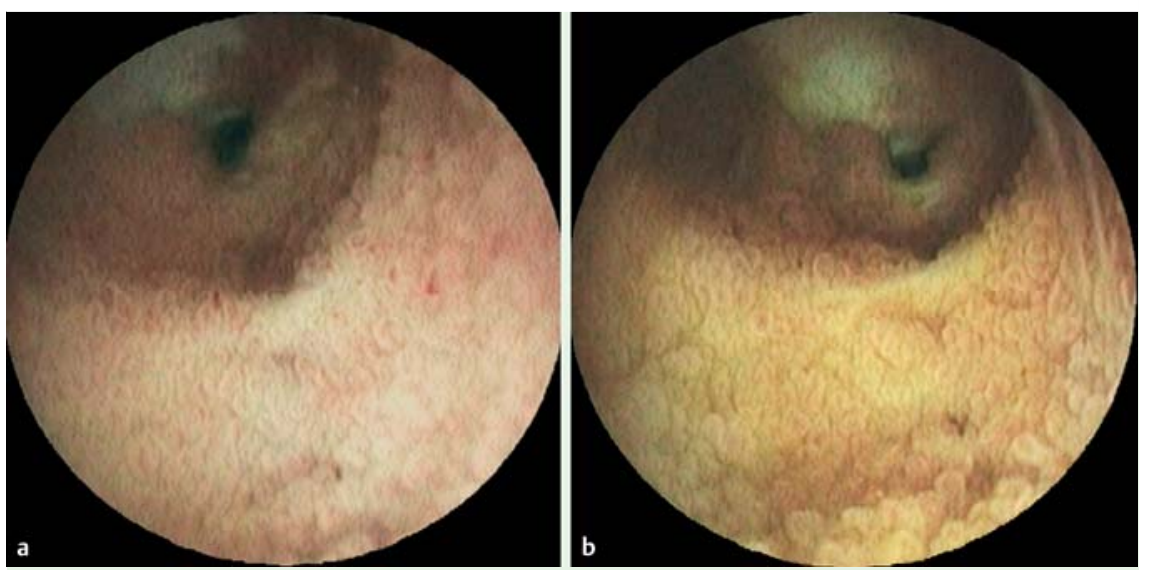

Fig. 5 Views during further choledochoscopies showing: a persistent reddish mucosa 2 weeks after the second RFA application, the edges of the ablated mucosa being hard to identify; $\mathbf{b}$ persistent granular lesions 2 months after the second RFA application, although the hyperemia and edema of the duct membrane have improved compared to the pretreatment image ( Fig. 4 a).

\section{Fei Wang, Quanpeng Li, Xianxiu Ge, Hong Yu, Junjie Nie, Lin Miao}

Institute of Digestive Endoscopy and Medical Center for Digestive Diseases, Second Affiliated Hospital of Nanjing Medical University, Nanjing, China

\section{References}

1 Todani T, Watanabe Y, Toki A et al. Classification of congenital biliary cystic disease: special reference to type Ic and IVA cysts with primary ductal stricture. J Hepatobiliary Pancreat Surg 2003; 10: 340-344

2 Shi LB, Peng SY, Meng XK et al. Diagnosis and treatment of congenital choledochal cyst: 20 years' experience in China. World J Gastroenterol 2001; 7: 732-734

3 Kumamoto T, Tanaka K, Takeda K et al. Intrahepatic cholangiocarcinoma arising 28 years after excision of a type IV-A congenital choledochal cyst: report of a case. Surg Today 2014; 44: 354-358

4 Wadsworth CA, Westaby D, Khan SA. Endoscopic radiofrequency ablation for cholangiocarcinoma. Curr Opin Gastroenterol 2013; 29: 305-311

5 Mavrogenis G, Deprez PH, Wallon J et al. Bile duct adenoma causing recurrent cholangitis: diagnosis and management with targeted Spyglass access and radiofrequency ablation. Endoscopy 2012; 44 (Suppl. 02): E290-E291
Bibliography

Dol http://dx.doi.org/

10.1055/s-0034-1367604

Endoscopy 2014; 46: E373-E374

(c) Georg Thieme Verlag KG

Stuttgart · New York

ISSN 0013-726X

\section{Corresponding author}

\section{Lin Miao, MD}

Institute of Digestive Endoscopy and Medical Center for Digestive Diseases

Second Affiliated Hospital of Nanjing Medical University

121 jiangjiayuan

Nanjing 210011

Jiangsu Province

China

Fax: +86-25-58509931

miaofrest@163.com 